\title{
Stirbt der Mann aus und wenn nicht, warum?
}

Ob Mann oder Frau biologisch das schwache Geschlecht verkörpert, darüber wird diskutiert, seit es Menschen gibt. Die Frage schien zunächst eindeutig entschieden, und zwar zu ungunsten des Manns, als vor einigen Jahren amerikanische Forscher einen vielbeachteten Artikel in "Nature“ veröffentlichten. Darin beschrieben sie einen raschen Gen-Verlust auf dem

Y-Chromosom. Entsprechende Hochrechnungen ergaben, dass dieses Chromosom in spätestens 100 Jahren vollständig verschwunden sein dürfte. Und dies müsste dann unweigerlich das Ende des männlichen Geschlechts und damit auch der sexuellen Fortpflanzung bedeuten.
Die Reaktionen auf die Vision einer Gesellschaft ohne Männer waren durchaus unterschiedlich. Nicht wenige Vertreter des weiblichen Geschlechts fanden das sich anbahnende Szenario als Befreiung. Dabei vergaßen sie allerdings, dass sie selbst bei allem Optimismus bzgl. des zeitlichen Vorlaufs wohl nicht mehr in den Genuss dieser biologischen Wohltat gekommen wären. Andere

Frauen machten sich

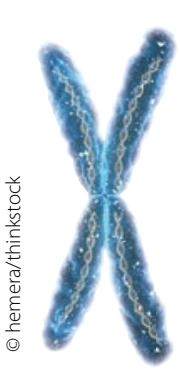

keinesfalls sicher ist, das die Natur nach dem Aussterben des Manns auf die Möglichkeit der Jungfernzeugung zurückgreifen würde, was übrigens auch nicht von allen Frauen als sinnvolle und zufriedenstellende Option angesehen wird.

Ob jetzt die Enttäuschung oder die Freude überwiegt, weiß ich nicht. Fakt jedoch ist: wenn überhaupt, so ist das Verschwinden des Manns kein aktuelles Thema; denn nach neuesten Erkenntnissen hat sich die Länge des YChromosoms in den letzen 25 Millionen Jahren nicht mehr verändert. So wird es auf dieser Erde sehr wahrscheinlich bis an das Ende aller Tage Mann und Frau geben, und das ist auch gut so, denn die meisten Frauen haben doch lieber einen Mann als gar keinen Ärger.

Dr. Peter Stiefelhagen *

\section{TROTZ HYPERURIKÄMIE}

\section{Ob sich eine Gicht entwickelt, bestimmt der Patient}

— Nur jeder Zehnte mit einer Hyperurikämie entwickelt eine Gicht. Eine Zwillingsstudie mit eineiigen und zweieiigen Zwillingen konnte zeigen, welchen großen Einfluss der Lebensstil auf die Entstehung der Krankheit hat.

Die 514 männlichen Zwillingspaare waren Teil einer prospektiven Kohortenstudie (National Heart, Lung and Blood Institute twin study). Zu Beginn der Studie waren die 253 eineiigen und 261 zweieiigen Zwillinge zwischen 42 und 55 Jahre alt. Sie wurden durchschnittlich 34 Jahre beobachtet. Die Harnsäure im Serum lag bei den eineiigen Zwillingen im Mittel bei 6,35 mg/dl, bei den zweieiigen bei $6,28 \mathrm{mg} / \mathrm{dl}$. Eine $\mathrm{Hy}$ perurikämie (Harnsäure $>7 \mathrm{mg} / \mathrm{dl}$ in allen drei untersuchten Proben) zeigte sich bei 40,5\% der Probanden. Während in der Gruppe der eineiigen Zwillinge 52\% in der Diagnose "Hyperurikämie" übereinstimmten, lag die Konkordanz bei den zweieiigen nur bei $24 \%$. Dies macht den erblichen Charakter der Hyperurikämie deutlich.
Die Lebenszeitprävalenz der Gicht war bei den eineiigen und zweieiigen Zwillingen ähnlich (11,9\% vs. 11,5\%). Der Ausgangswert der Harnsäure war bei den Gichtpatienten höher als bei denen, die keine Gicht entwickelten (7,05 mg/dl vs. 6,21 mg/dl).

Die genetischen Analysen für die Gicht legen nahe, dass die individuellen Unterschiede in der Lebenszeitprävalenz von Zwillingspaaren durch verschiedene Umweltfaktoren beeinflusst werden. Die genetische Veranlagung scheint bei der Entwicklung der Gicht eine untergeordnete Rolle zu spielen. $45,1 \%$ der phänotypischen Unterschiede konnten Umwelteffekten zugeschrieben werden, denen beide Zwillinge gleicherma-

ßen ausgesetzt waren, der Rest ging auf das Konto individueller Lebensfaktoren. So gelten beispielsweise eine Adipositas oder übermäßiger Alkoholkonsum als Risikofaktoren für die Entwicklung einer Gicht.

Die Studie betont einerseits den erblichen Charakter der Hyperurikämie, lässt aber auch den starken Einfluss von Umweltfaktoren für die Entwicklung einer Gicht erkennen. Daraus leiten sich nach Ansicht der Autoren wichtige Hinweise sowohl für die Prävention als auch für die Therapie der Erkrankung ab. Größere Zwillingsstudien müssten u. a. klären, ob die bei männlichen Zwillingen gefundenen Ergebnisse auch auf Frauen übertragbar sind.

ST $\equiv$

Krishnan E et al. The American Journal of Medicine 2012;125:499-504

Weichteiltophus am linken Großzehengrundgelenk bei Gicht. 